\title{
Reforming State Owned Enterprises in China: Effects of WTO Accession
}

\author{
Claustre Bajona \\ Ryerson University \\ Toronto, ON M5B 2K3, Canada \\ Tianshu Chu \\ South Western University of Finance and Economics \\ Chengdu, Sichuan 610074, China
}

April 28, 2009

\begin{abstract}
In December 2001 China became a member of the World Trade Organization (WTO). By signing the accession protocol, China not only agreed to reform its trade policy, but it also accepted regulations that implied reductions on government subsidies to the state-owned sector. In this paper we claim that the latter, largely ignored in the literature, generate important welfare gains that need to be attributed to WTO accession. We develop a dynamic general equilibrium model with state and private enterprises. We calibrate the model to the Chinese economy and we quantitatively assess the economic effects of reducing subsidies to the state sector as required by the WTO. We find the welfare benefits of such reduction in subsidies to be substantial. Using the context of China, this paper identifies a new channel through which WTO accession increases a country's welfare: it induces reforms on domestic subsidies which lead to an increase in economic efficiency.
\end{abstract}

${ }^{*}$ We are very grateful to Timothy Kehoe for his help and support with this and previous versions of this paper. We also thank Sonia Wong and Jim Schmitz for valuable discussions, and Loren Brandt, Pere Gomis-Porqueras, Rana Hasan, David Kelly, Lee Ohanian, Adrian Peralta-Alba, and Xiaodong Zhu, as well as all the participants at the University of Toronto Macroeconomics seminar, for insightful comments. All remaining errors are our own. Send comments to cbajona@ryerson.ca. 


\section{Introduction}

In December 2001, after fifteen years of negotiations, China became the 143rd member of the WTO in what was seen as an important step towards world economic integration. In signing the WTO accession protocol, China committed itself to follow in a set of rules and regulations aimed at facilitating international trade. Most of these regulations required changes in trade policy, such as tariff reduction, elimination of quotas, and improved accessibility to domestic markets by foreign competitors. An extensive literature has focused on the potential effects of these trade policy reforms on China and on the rest of the world (see, for instance, World Bank 2004 and the studies cited therein.)

Less attention has been given to another set of regulations, also included in China's accession documents, involving provisions that lead to deeper reforms in China's state-owned sector. ${ }^{1}$ This second set of provisions could potentially have substantial economic effects on the Chinese economy, given that China's state-owned enterprises (SOEs) are large, inefficient, and heavily subsidized. We argue that the welfare benefits derived from reforms on the SOE sector promoted by WTO accession are important, and should be added to any welfare gains derived from the pure effects of trade policy reform. Assessing the welfare gains derived form this set of provisions is the objective of this study.

In this paper we develop a dynamic general equilibrium model in order to assess the welfare benefits of introducing the reforms on the SOE sector implied by China's WTO accession documents. The basis of our framework is a one-sector neoclassical growth model with exogenous technological change where two types of producers coexist: SOEs and private enterprises. SOEs and private enterprises produce a perfectly substitutable good, using a constant returns to scale technology. SOEs differ from private enterprises in three aspects: their ability to choose employment levels, the subsidies that they receive from the government, and their productivity levels. In particular, SOEs are required to maintain a minimum level of employment, and receive government subsidies in exchange. ${ }^{2}$ SOEs receive two types of subsidies: direct subsidies, such as cash payments used to cover production losses, and capital subsidies, or low-interest loans from state banks. Given that the magnitude of the effects of WTO accession on capital subsidies is hard to assess, in this paper we mainly concentrate in studying the effects of WTO accession on direct subsidies, and give some estimates of the economic effects of reducing the capital subsidies. Regarding productivity

\footnotetext{
${ }^{1}$ These provisions are mainly included in Annex 1A, Agreement on Subsidies and Countervailing Measures, of the WTO's legal document on the Uruguay Round Agreements.

${ }^{2}$ See Yin (2001) for evidence of the government's use of SOEs to maintain employment levels.
} 
levels, we find that SOEs are less efficient than private firms operating in the same industry. This difference in efficiency between SOEs and private enterprises is crucial in determining the findings of this paper, as we explain below.

In this paper we take SOE policy and WTO accession as exogenous policy decisions. An interesting question, left for further research, is whether similar SOE reforms would have occurred in China independently of WTO accession. Using a political economy approach, Branstetter and Feenstra (2002) find that regional and local governments favor state-owned enterprises. We take their results as indicative of the existence of special interest groups that benefit from SOEs and thus may create political pressures to keep the SOE subsidies high. Linking SOE reform to WTO accession may be a way to overcome these pressures.

We calibrate the parameters of the model to the Chinese economy and compare the transitional dynamics of several economies that reform the SOE sector along different dimensions with a benchmark economy that does not reform its SOE sector. We find that the welfare gains of WTO-induced reforms on direct subsidies to SOEs are of 1.5 percent in terms of equivalent variation. ${ }^{3}$ This increase in welfare is the result of the combination of two effects: a factor reallocation effect and a capital accumulation effect. The factor reallocation effect is static in nature, and implies a movement of factors of production from the SOE sector to the more efficient private sector. The capital accumulation effect is dynamic in nature and arises because the change in subsidies affects the interest rate and, therefore, the economy's incentives to accumulate capital. When capital subsidies are also reduced over the reform period, welfare gains increase to 5.4 percent relative to the benchmark. The additional gains are mainly obtained from a deeper reduction in SOE employment that is needed to comply with WTO requirements. Total factor productivity (TFP) levels are consistently above benchmark during the transition in all reformed economies.

The magnitude of the factor reallocation effect, and the subsequent increase in TFP, is a key determinant of the welfare gains of SOE reform. Therefore, calibrating the relative inefficiency of the SOE sector is crucial in this study. The calibration procedure, which is explained in detail in section 5, delivers that private firms are 38 percent more productive than SOEs. These relative inefficiencies are consistent with results in Schmitz (1997), who finds private firms to be more productive than SOEs operating the same industries.

The analysis of the transitional dynamics illustrates the differences in transition paths between the reformed economies and the benchmark. The reformed economies grow at a slower rate than the benchmark economy in the pre-reform periods, as individuals hold on

\footnotetext{
${ }^{3}$ That is, the representative consumer in the benchmark economy needs a permanent increase in consumption of 1.5 percent to be as well off as the representative consumer in the reformed economy.
} 
their investments until the reforms start, and grows faster during the reform periods, arriving sooner to its balanced growth path.

This paper's main message goes well beyond the case of China's WTO accession: once domestic policy reforms associated with a trade agreement are taken into account, the total benefits of trade liberalization may substantially exceed the benefits derived from pure tariff reduction, especially in countries with large state sectors. The methodology developed in this paper is suitable for analyzing the economic effects of industrial subsidy reforms both in countries with large state sectors and in countries with highly subsidized industrial sectors.

This paper relates to several existing literatures. First, it relates to the literature that analyzes the effect of domestic distortions on a country's total factor productivity. Two recent papers in this literature are Restuccia and Rogerson (2008) and Hsieh and Klenow (2007). Restuccia and Rogerson (2008) show that distortions that create heterogeneity in the prices faced by different firms in the same sector can have strong effects on output and real GDP. Hsieh and Klenow (2007) analyze the effect on TFP of misallocation of factors of production in China and India. Both of these papers treat the distortions as abstract, and do not focus on specific policies that generate the misallocation of resources. In contrast, our paper presents a specific set of policies that are responsible for this misallocation and it quantifies their effects.

Second, the paper relates to the vast literature that studies state-owned enterprises. Two papers in this literature are directly related to ours. Ghosh and Whalley (2000) also conclude, in a different setting, that tariff reduction may have different implications in economies with sizable state sectors. Schmitz (1997) is one of the few papers that presents measures of the relative productivity of the SOE sector with respect to the private sector. Schmitz's paper studies the impact on average labor productivity of having SOEs in the investment sector using a general equilibrium framework. Even though the methodology used in his study is similar to ours, the papers differ in several aspects: Schmitz concentrates on the presence of SOEs in the investment sector, he does not consider the link between trade liberalization and the SOE sector, and he does not study the case of China.

Third, the paper also contributes to the literature that investigates the economic effects of China's accession to the WTO (see, for instance, Fang and Zheng 2001, Ianchovichina and Martin 2001 and 2004, Lardy 2002, McKibbin and Tang 2000, Rumbaugh and Blancher 2004, Walmsley and Hertel 2001, Wang 1999, Wen 2000, and the studies cited there in). These studies concentrate on the gains from pure changes in trade policy and do not consider the effects of WTO on the state sector. This paper complements this literature by pointing out another source of benefits to China from WTO accession. To the best of our knowledge, our 
paper is the first one to quantitatively analyze the economic effects of China's WTO accession on SOE reform, even though other studies have mentioned the fact that the Chinese gains of economic liberalization derived from internal reforms may be important (see, for instance, Cheng 2000, Claro 2001, Frazier 1999, Lardy 2002, and Rumbaugh and Blancher 2004).

Finally, the paper contributes to the literature that analyzes China's state-owned sector. Most of these studies are concerned with the performance of China's SOEs during the reform period (Hay, Morris, Lin, and Yao 1994, Huang and Duncan 1997, Li 1997, Lin, Cai, and Li 1998, Perkins 1994, Sicular 1995, and Wei, Varela, and Hassan 2002 are some examples). Our paper is closer to Yin (2001) and Brandt, Hsieh, and Zhu (2007). Both papers analyze the effect of the reallocation of workers from the SOE sector to the private sector on China's economic growth. In contrast to this paper, Yi's study is only theoretical and does not quantify the magnitude of the effects implied by his model. Brandt, Hsieh, and Zhu (2007) is empirical, but does not focus on how the accession to the WTO affected the movement of workers out of the state sector.

This paper is organized as follows. In section 2 we briefly describe the Chinese economy and the conditions under which China entered the WTO. Section 3 presents the model economy. Section 4 presents analytical results for a version of the model without capital adjustment costs. Section 5 contains the calibration of the model to the Chinese economy. Section 6 presents numerical results. Sensitivity analysis is performed in section 7 . Section 8 considers the effect of reducing capital subsidies, and section 9 concludes.

\section{China's SOE Reform and the WTO}

The Chinese economy was centrally planned prior to 1978. That year, China's leader Deng Xiaoping introduced a series of reforms that gradually opened the economy, implemented market-oriented policies, and allowed non-state ownership to exist and develop. Following the Soviet Union's economic structure, Chinese industries were mostly state-owned at the beginning of the economic reform. The state sector virtually dominated all non-farm industries, accounting for 78 percent of industrial output in 1978. Reforming the SOE sector has been a crucial aspect of economic reform in China. Starting in 1983, the government tried different approaches aimed at improving the efficiency and profitability of the sector. The task proved difficult and, even though the SOEs' share of GDP was significantly reduced by 1997, the sector's overall profitability deteriorated during this period (see Lin, Cai, and Li, 1998.) Furthermore, SOEs remain less productive and less profitable than firms of other 
types of ownership. ${ }^{4}$

The existence of SOEs creates a dual market that affects the Chinese economy mainly by promoting an inefficient allocation of resources. Government subsidies, cheap loans from the state owned commercial banks, and laws that protect SOEs' workers against layoffs keep the SOEs operating even though half of them are making losses (Lin, Cai, and Li, 1998.) Despite this inefficiency, the Chinese public sector still accounts for a big share of capital formation (over 65 percent in the period 1994-97) and consumes most of China's savings (in the order of 70-80 percent) through cheap loans from state banks. This represents a burden to the financial system, since as much as 40 percent of these loans may be non-performing (Chen and Divan, 2000.)

WTO requirements that explicitly target the SOE sector are stated in Annex B of the "Agreement on Subsidies and Countervailing Measures" (SCM), which lists subsidies that are to be phased out upon China's accession to the WTO. Part I of the Annex mentions "subsides provided to certain SOEs which are running at a loss," given in the form of grants or tax breaks, that are to be phased out in a period of 5 years. For 1997 the amount of direct subsidies included under the provision amounted to 9.6 billion RMB, or about 26 percent of total direct SOE subsidies for that year.

SOE subsidies are also explicitly mentioned on paragraphs 172 and 173 of the Report of the Working Party on the Accession of China where, in response to concerns about the comprehensiveness of the subsidies listed in Annex B of the SCM, China pledges that "China's objective is for SOEs, including banks, to run on a commercial basis and be responsible for their profits and losses." Nevertheless, the report does not stipulate a timetable for the introduction of these capital market reforms, which damages the report's credibility. Furthermore, any measure induced by WTO accession that increases competition may have an implicit effect on the SOE sector. In this paper we consider one of those measures, the opening of the financial sector to foreign banks, and the effects that it may have on the preferential treatment of the SOEs by state banks. According to the WTO accession agreement, China is to gradually open its financial sector to foreign banks, which should receive national treatment five years upon accession. The increase in competition in the financial sector brought by foreign banks will require state banks to be more profit-based in order to survive and, therefore, to reduce their lending to non-performing SOE. In this paper, we take China's pledge of running state banks on a commercial basis as a sign that SOE's capital subsidies will most likely be reduced during the reform period, but we do not attempt to

\footnotetext{
${ }^{4}$ See Hay, Morris, Lin, and Yao (1994) and Wei, Varela, and Hassan (2002) for a description of the SOEs' economic performance.
} 
quantify by how much.

\section{The Model}

In this paper we develop a dynamic general equilibrium model to quantitatively assess the economic effects of SOE reforms in an economy where subsidized government enterprises co-exist with private competitive firms. We use the term private firms in a very general sense, including within it a combination of foreign firms and domestic enterprises which are not covered by government subsidies.

The framework that we use in this paper is a one-sector, closed economy, neoclassical growth model with two types of firms. The closed economy assumption is taken in order to isolate the effects of subsidy reduction, induced by WTO accession, from those of tariff reduction. By analyzing these effects in isolation, this paper presents a new channel through which trade policy affects the economy: implied reforms on domestic industrial subsidies.

\subsection{Producers}

There are two types of producers in the economy: SOEs and private firms. Private firms and SOEs differ in three aspects: their technology levels, their ability to choose their labor input, and their cost of capital. Technology differences are taken as exogenous and calibrated to the data. The labor input and the cost of capital are determined by the market in the private sector, but are influenced by the government in the SOE sector. In particular, SOEs hire labor at market prices, but are required to keep employment above a pre-designed level, which we denote the minimum labor requirement. ${ }^{5}$ In exchange for keeping a high level of employment, the government is committed to cover any losses incurred by the SOEs with direct cash payments. We call these cash payments direct subsidies. SOEs also rent capital at market prices, but receive a capital subsidy for each dollar worth of capital rented. If we denote the rental rate of capital by $R$, the state enterprises rent capital at a rate $(1-s) R$. These assumptions about the SOE sector are designed to capture the SOEs' role as promoters of employment, as well as the two main forms of subsidies to the SOE sector used by governments: direct subsidies and preferential treatment by state banks in form of lower interest rates and easy access to credit.

The production function of a firm with ownership of type $s, s=P, G$, is defined as:

$$
Y_{s t}=A_{s} \gamma^{(1-\alpha) t} K_{s t}^{\alpha} L_{s t}^{1-\alpha},
$$

\footnotetext{
${ }^{5} \mathrm{Yi}(2001)$ argues that SOEs are seen by the government as promoters of employment.
} 
where $Y_{s t}$ is the production of the aggregate good by sector $s$ at period $t, K_{s t}$ and $L_{s t}$ are the capital and labor inputs, respectively, and $A_{s} \gamma^{(1-\alpha) t}$ is the productivity parameter. Notice that we allow for the technologies of the private and government enterprises to differ in the technology parameter, but we take the capital share of income to be the same in both private enterprises and SOEs. Therefore, in this model, any differences that may exist in the capital-labor mixture used by the private and the state sectors are attributed to government policy.

Both SOEs and private firms maximize profits taking prices and government policies as given. In making this assumption, we follow studies by Perkins (1994) and Yin (1998 and 2001) that argue that the contract management responsibility system introduced in China in 1984, which allows managers of SOEs to keep any above-target profits, has encouraged managers to seek profit maximization. Therefore, the SOE problem consists of maximizing profits given the labor requirement imposed by the government and the capital subsidy rate. If the minimum labor requirement is not binding, the SOE makes zero profits. If the minimum labor requirement is binding, the SOE may make negative profits. In this case, a direct subsidy is used to cover the losses. We assume that there are $M$ identical SOEs, each facing a minimum labor requirement of $\bar{L} / M{ }^{6}$ It is easy to show that the aggregate decisions in the state-owned sector are equivalent to the decisions in an alternative environment with only one SOE firm that faces a minimum labor requirement of $\bar{L}$. Since we are only interested in the aggregate SOE sector, in the rest of the paper we derive conditions under the single-SOE assumption, keeping in mind that in the disaggregated world, a minimum labor requirement applies to each firm. In what follows, we use the terms "SOE sector" and "SOEs" interchangeably.

The first order conditions for the private firms are:

$$
\begin{gathered}
(1-\tau) \gamma^{(1-\alpha) t} A_{P} \alpha K_{P t}^{\alpha-1} L_{P t}^{1-\alpha} \leq R_{P t} \text { with equality if } K_{P t}>0 \\
(1-\tau) \gamma^{(1-\alpha) t} A_{P}(1-\alpha) K_{P t}^{\alpha} L_{P t}^{-\alpha} \leq w_{t} \text { with equality if } L_{P t}>0,
\end{gathered}
$$

where $\tau$ is the tax rate on firms' output, $R_{P t}$ is the rental rate of capital in period $t$, and $w_{t}$ is the wage. Similarly, the first order conditions for the SOE can be written as:

$$
(1-\tau) \gamma^{(1-\alpha) t} A_{G} \alpha K_{G t}^{\alpha-1} L_{G t}^{1-\alpha} \leq R_{G t}(1-s) \text { with equality if } K_{G t}>0
$$

\footnotetext{
${ }^{6}$ Notice that the minimum labor requirement in this environment needs to be given at the firm level, since for any aggregate minimum labor requirement $\bar{L}$, redistributing labor across SOEs changes aggregate profits. Even though production occurs under constant returns to scale, the labor constraint makes the number of SOEs relevant in this model. We thank an anonymous referee for pointing this fact to us.
} 


$$
(1-\tau) \gamma^{(1-\alpha) t} A_{G}(1-\alpha) K_{G t}^{\alpha} L_{G t}^{-\alpha} \leq w_{t} \text { with equality if } L_{G t}>\bar{L}
$$

Here $\bar{L}$ denotes the minimum labor requirement set by the government for the SOE.

Given a period's endowment of capital and labor, we can analytically solve for the amount of inputs used and output produced in each sector. By combining the first order conditions (2)-(5) it is easy to see that private firms coexist with the SOE if and only if

$$
A_{G} / A_{P} \leq(1-s)^{\alpha}
$$

That is, the private firms' productivity relative to the SOE has to be high enough, given the capital subsidy rate. If this condition is not satisfied, the private firms cannot compete with the subsidized SOE and exit the market. In the rest of the paper, we assume that this condition is satisfied. ${ }^{7}$ Therefore, the SOE hires just enough labor to fulfill the minimum labor requirement, and both private firms and the SOE coexist. In equilibrium SOE profits (losses if negative) are given $b^{8}$ :

$$
\Pi_{G t}=(1-\tau)(1-\alpha) Y_{G t}-w_{t} \bar{L}
$$

In our framework the goods produced by the state and the non-state enterprises are perfect substitutes $\left(Y_{t}=Y_{P t}+Y_{G t}\right.$, where $Y$ is denotes total output). Notice that as long as the minimum labor requirement is positive the state enterprises always produce a positive amount of output. Furthermore, given that private enterprises behave competitively, they co-exist with state enterprises only if the minimum labor requirement for the state enterprises is binding (that is, if the SOEs are inefficient relative to the private sector).

\subsection{Consumers}

The consumption side of the economy at any given period $t$ is characterized by $N_{t}$ identical, infinitely-lived consumers who are endowed with one unit of time which they supply inelastically. We assume that population grows at a constant rate, so that $N_{t+1}=n N_{t}$, with $n>0$. Consumers derive utility from the consumption of the aggregate good. The representative

\footnotetext{
${ }^{7}$ This condition is satisfied by our calibrated parameters in section 5 .

${ }^{8}$ The SOE's problem is $\Pi_{G t}=\max \left[(1-\tau) \gamma^{(1-\alpha) t} A_{G} K_{G t}^{\alpha} L_{G t}^{1-\alpha}-w_{t} L_{G t}-R_{G t}(1-s) K_{G t}\right]$, subject to $L_{G t} \geq \bar{L}$. Assuming that the labor condition is binding, $L_{G t}=\bar{L}$. Multiplying (4) by $K_{G t}$ and using the notation in (1), we obtain $R_{G t}(1-s) K_{G t}=(1-\tau) \alpha Y_{G t}$. Replacing these expressions in the objective function produces equation (7).
} 
individual solves the following problem:

$$
\begin{array}{ll}
\max & \sum_{t=0}^{\infty} \beta^{t} N_{t}\left(c_{t}^{\rho}-1\right) / \rho \\
\text { s.t. } & c_{t}+n a_{t+1}=w_{t}+\left(1+r_{t}\right) a_{t}+T C_{t} / N_{t} \\
& a_{t} \geq-A \\
& a_{t}=q_{P t-1} k_{P t}+q_{G t-1} k_{G t} \\
& k_{P 0}, k_{G 0} \text { given, }
\end{array}
$$

where $c_{t}$ is consumption, $a_{t}$ represents the assets held by the individual, $w_{t}$ and $r_{t}$ are the wage rate and the return to savings, respectively, and $T C_{t}$ represents net transfers from the government to consumers. The intertemporal elasticity of substitution is given by $1 /(1-\rho)$, where $\rho<1$. Here, and in the rest of the paper, lowercase letters indicate variables in per capita terms.

In the definition of $a_{t}, q_{s t-1}$ represents the return to capital of type $s(s=P, G)$ invested at $t-1$ to be used in period $t$, and $k_{s t}$ is the amount of capital in sector $s$ available in period $t$. The presence of adjustment costs to capital in this model (see section 3.4 below) introduces imperfect capital flows between SOEs and private firms. Returns to capital may differ across sectors and, therefore, consumers see capital in the SOEs and capital in the private firms as different assets.

\subsection{Government}

The government in this economy is modeled as a budget constraint. It obtains revenue from taxes on producers' output, $T$, and uses the proceeds to fund purchases of the aggregate good, $G$, which is determined exogenously, and to finance subsidies to the SOE sector (interest subsidies, $S_{K}$, and direct subsidies, $S_{L}$, where $S_{L}=-\Pi_{G}$ and $S_{K}=s R_{G} K_{G}$ ). Any excess funds (costs) are transferred to (born by) consumers in the form of net government transfers, $T C$. Modeled this way, the government balances the budget every period. Net government transfers can be interpreted as the government surplus (deficit if negative). The budget constraint that the government faces is:

$$
G+S_{K}+S_{L}+T C=T
$$

\subsection{Capital accumulation and market clearing}

The output produced in the economy can either be consumed or invested and used by producers to increase their capital stock:

$$
N_{t} c_{t}+G_{t}+I_{P t}+I_{G t}=Y_{t}
$$


where $I_{s t}$ is the investment in sector $s(s=P, G)$ at period $t$.

We assume that there exist adjustment costs to capital. Capital cannot move across sectors, it depreciates at the constant rate $\delta$, and can only be replaced or increased with new investment. We follow the tradition of Lucas and Prescott (1971) and model the adjustment costs in the following way:

$$
K_{s t+1}=\phi\left(\frac{I_{s t}}{K_{s t}}\right) K_{s t}+(1-\delta) K_{s t}
$$

where $\delta$ is the depreciation rate of capital, and the adjustment function $\phi(\cdot)$ is assumed to be strictly increasing and strictly concave in the investment-capital ratio, and to satisfy $\phi(n \gamma-1+\delta)=n \gamma-1+\delta$ and $\phi^{\prime}(n \gamma-1+\delta)=1$. These last two properties are necessary for capital to depreciate at the rate $\delta$ in the balanced growth path and, thus, for the adjustment costs not to have any effect in the long run. We use a one-parameter adjustment cost function that satisfies the properties mentioned above adapted from Fernández de Córdoba and Kehoe (1999) and modified to be used in an economy with exogenous technological change and population growth:

$$
\phi(x)=\left((n \gamma-1+\delta)^{1-\eta} x^{\eta}-(1-\eta)(n \gamma-1+\delta)\right) / \eta, \quad 0<\eta \leq 1 .
$$

In this specific function the $1 /(1-\eta)$ is the elasticity of the investment-to-capital ratio with respect to the Tobin's q (Kouparitsas, 1998). Notice that having capital adjustment costs in the model slows down the transition to the balanced growth path and, therefore, it may reduce the welfare gains of policy reform. In the calibration section we do sensitivity analysis and show how the results change with the degree of adjustment costs.

Feasibility in the labor market implies that the demand for labor equals the total amount of workers available in the country:

$$
L_{G t}+L_{P t}=N_{t}
$$

The aggregate capital stock in the economy (used to compute TFP) is defined as:

$$
K_{G t}+K_{P t}=K_{t}
$$

Finally, consistency between per-capita and total variables implies that $k_{t}=K_{t} / N_{t}$ for all $t$.

Given that we are interested in changes in TFP and output, it is important to summarize the different sources of growth in this model. The only source of long run growth is exogenous technological change, which we denote by $\gamma$. Deviations from trend during the transition are due to accumulation of capital and movements of resources between SOEs and private firms. 


\subsection{Definition of equilibrium}

Definition 1 Given government policies and initial endowments of capital in each sector $K_{P 0}, K_{G 0}$, the equilibrium of this economy is determined by a set of sequences: consumer's decisions $\left\{c_{t}, a_{t}\right\}$, private firms' decisions, $\left\{K_{P t}, L_{P t}, Y_{P t}\right\}$, SOEs' production decisions, $\left\{K_{G t}, L_{G t}, Y_{G t}\right\}$, investment decisions, $\left\{I_{P t}, I_{G t}\right\}$ and prices, $\left\{q_{P t}, q_{G t}, w_{t}, r_{t}, R_{P t}, R_{G t}\right\}$, such that the consumer and producers' (SOEs and private enterprises) problems are satisfied, all markets clear, the laws of motion for capital in each industry and sector are satisfied, and the consistency conditions are satisfied.

In this study we restrict ourselves to equilibria that converge to a balanced growth path. Following standard procedure in models with exogenous technological change, we solve for equilibrium by constructing a stationary economy the solution of which is equivalent to the detrended solution of our economy (the trend determined by the exogenously given long run growth rate.) That is, if $\hat{\nu_{t}}$ is an equilibrium variable of the stationary economy, the corresponding equilibrium variable in the model economy is $\nu_{t}=\hat{\nu}_{t} \gamma^{t}$ for quantity variables (except labor inputs) and the wage, and $\nu_{t}=\hat{\nu_{t}}$ for prices and labor inputs. The corresponding stationary economy is characterized by the same equations as our model economy, with the following changes:

(1) The production functions of the transformed economy become, for $s=P, G$ :

$$
\hat{Y}_{s t}=A_{s} \hat{K}_{s t}^{\alpha} \hat{L}_{s t}^{1-\alpha}
$$

(2) The law of motion of capital in the transformed economy is:

$$
\gamma \hat{K}_{s t+1}=\phi\left(\frac{\hat{I}_{s t}}{\hat{K}_{s t}}\right) \hat{K}_{s t}+(1-\delta) \hat{K}_{s t} .
$$

(3) Finally, the discount factor of the stationary economy is $\hat{\beta}=\beta \gamma^{\rho}$ and the budget constraint:

$$
\hat{c}_{t}+n \gamma \hat{a}_{t+1}=\hat{w}_{t}+\left(1+r_{t}\right) \hat{a}_{t}+\hat{T C_{t}} / N_{t}
$$

\subsection{Policy experiments: a road map}

In the rest of the paper we use the model described above to analyze the effect on output, TFP, and welfare of reducing direct subsidies and capital subsidies. At any given period, aggregate TFP is jointly determined by the productivity of the SOE and the private sector, as well as the shares of inputs in each of the sectors. A reduction in subsidies reallocates 
resources from less productive SOEs to more productive private firms (resource reallocation effect). The economy becomes more efficient and aggregate TFP, output, and welfare increase. A reduction in subsidies also changes investment (capital accumulation effect).

In order to obtain intuition on the way direct subsidies and capital subsidies affect the economy, section 4 derives analytical results for a version of the model without adjustment costs to capital. In particular, we show how the labor requirement and the capital subsidy rate determine aggregate productivity (proposition 1) and the steady state levels of capital and labor of the stationary economy (proposition 2). Simulation results for the full version of the model are presented in section 6. We distinguish a pre-reform period (1997-2000), a reform period (2001-2005), and a post-reform period (2006 on). In the pre-reform period the capital subsidy rate stays constant at its calibrated value, and the direct subsidies decrease at a fixed (calibrated) rate. In the post-reform period, the capital subsidy rate and the minimum labor requirement are kept at their corresponding level in the last year of the reform period (2005). ${ }^{9}$ We compare two scenarios that differ in the behavior of the policies during the reform period: (i) a benchmark economy in which the capital subsidy rate stays constant and the direct subsidies are reduced at the same rate as in the pre-reform period; and (ii) a direct subsidies economy, where the capital subsidy stays constant and the direct subsidies are reduced according to WTO requirements. Section 8 analyzes the effects of changes in capital subsidies by comparing the benchmark economy to two additional scenarios: a (iii) capital subsidies economy in which the capital subsidy rate decreases at a constant rate during the reform period, and the minimum labor requirement stays constant (this increases direct subsidies, since now SOEs are making higher losses); and a (iv) both subsidies economy where the capital subsidy rate decreases in the same way as in the previous scenario, and direct subsidies are reduced according to WTO requirements (through a reduction in the minimum labor requirement).

\section{Model without adjustment costs to capital}

This section presents analytical results for a version of the model without capital adjustment costs (that is, we set $\eta=1$ ). Adjustment costs to capital reduce the ability to move capital from one sector to the other and, therefore, have implications for investment and capital accumulation along the equilibrium path. Eliminating such costs equalizes the rate of return to capital across sectors and speeds up convergence to the balanced growth path. Notice

\footnotetext{
${ }^{9}$ In all scenarios the reduction in direct subsidies is achieved through changes in the minimum labor requirement.
} 
that since we have assumed that adjustment costs to capital do not have a role in the long run, the steady state results in this section apply exactly to the general version of the model.

\subsection{SOE shares}

Assume that the period endowments of capital, $K$, and labor, $N$, are given. From the first order conditions (2)-(5) with the feasibility conditions (13)-(14) we can solve for capital and output in each sector as functions of the total capital endowment in the economy and parameter values. Define $B \equiv\left[(1-s)\left(A_{P} / A_{G}\right)\right]^{1 /(1-\alpha)}$ and $H \equiv \bar{L}+B(N-\bar{L})$. Capital in each sector is given by:

$$
\begin{gathered}
K_{G}=\frac{\bar{L}}{H} K, \\
K_{P}=K-K_{G} .
\end{gathered}
$$

Output in each sector can be written as:

$$
\begin{gathered}
Y_{G}=A_{G}\left(\frac{K}{H}\right)^{\alpha} \bar{L} \\
Y_{P}=A_{P}\left(\frac{B K}{H}\right)^{\alpha}(N-\bar{L}) .
\end{gathered}
$$

Since output from both sectors are perfect substitutes, total output in the period is given by:

$$
Y=Y_{P}+Y_{G}=A(s, \bar{L}) K^{\alpha} N^{(1-\alpha)}
$$

where

$$
A(s, \bar{L}) \equiv A_{G} \frac{\bar{L}+B(N-\bar{L}) /(1-s)}{(H)^{\alpha} N^{1-\alpha}} .
$$

Therefore, given the policy parameters $(s, \bar{L})$, our model without capital adjustment costs is equivalent to a one sector growth model with only one type of firm and with production function $F(K, L)=A(s, \bar{L}) K^{\alpha} N^{(1-\alpha)}$.

The parameter $A(s, \bar{L})$, which measures total factor productivity in the economy, is a function of both the capital subsidy rate and the minimum labor requirement, as well as the productivity parameters $A_{P}$ and $A_{G}$. The following proposition states the behavior of the TFP parameter $A(s, \bar{L})$ with respect to the subsidy policies. 
Proposition 1 Consider a version of the model economy without adjustment costs to capital. Let $0 \leq s<1$ be the capital subsidy rate and $0<\bar{L}<N$ be the SOE's minimum labor requirement. Assume that the period factor endowments $K$ and $N$ are given. The total factor productivity parameter $A(s, \bar{L})$ described in (23) satisfies:

1. $A(s, \bar{L}) \in\left[A_{G}, A_{P}\right]$, with $A(s, 0)=A_{P}, A(s, N)=A_{G}$, and $A(0, \bar{L})>A_{G}$.

2. $\partial A / \partial \bar{L} \leq 0$, with equality only if both $s=0$ and $A_{G}=A_{P}$.

3. $\partial A / \partial s \leq 0$ with equality only if $s=0$.

This proposition is easily proved by taking derivatives on the expression for $A(s, \bar{L})$. Detailed derivations can be found in the appendix.

Proposition 1 implies that, in this economy, increasing SOE employment comes at the cost of lower overall productivity. This is a consequence of the resource allocation effect: higher SOE employment implies a higher proportion of factors used in the less productive sector and thus lower aggregate productivity. Higher capital subsidy rates have a similar effect: taking the period capital stock as fixed, a higher proportion of capital is used in the less productive sector, reducing overall productivity.

The SOE shares of output, capital, and labor are important variables in this model. Given the period capital and labor endowments, we can solve for these shares analytically. Define $\theta_{i}, i=Y, K, L$, as the SOE share of total output, capital, and labor, respectively. By the assumptions of the model we have $\theta_{L}=\bar{L} / N$. Using the expressions for SOE capital and output above, we obtain:

$$
\begin{gathered}
\theta_{K}=\frac{\bar{L}}{\bar{H}}, \\
\theta_{Y}=\frac{\bar{L}}{\bar{L}+B(N-\bar{L}) /(1-s)} .
\end{gathered}
$$

Notice from these expressions that if $s>0$, then $\theta_{K}>\theta_{Y}$. Therefore, as long as there are subsidies to capital, the SOE share of capital should be higher than the SOE share of output, with the ratio being non-monotone in the subsidy rate.

\subsection{Steady state}

In this section we solve for the steady state of the stationary economy analytically. Using the first order conditions from the consumer's problem we obtain the rental rate of capital 
in steady state:

$$
\hat{r}=\frac{(1+\gamma)^{1-\rho}}{\beta}-1+\delta
$$

By replacing this expression in the first order condition for the SOEs, (4), and using expression (18) for the SOE capital, we can solve for the steady state level of capital and output as functions of SOE policies:

$$
\begin{gathered}
\hat{K}=\left(\frac{(1-\tau) \alpha A_{G}}{\hat{r}(1-s)}\right)^{1 /(1-\alpha)} H \\
\hat{Y}=A(s, \bar{L}) \hat{K}^{\alpha} N^{(1-\alpha)}
\end{gathered}
$$

The next proposition states how $\hat{K}$ and $\hat{Y}$ change when the policy parameters change.

Proposition 2 Consider a version of the stationary model economy without adjustment costs to capital. Let $0 \leq s<1$ be the capital subsidy rate and $0<\bar{L}<N$ be the SOE's minimum labor requirement. If $\hat{K}$ and $\hat{Y}$ denote the steady state levels of capital and output of the stationary economy, then:

1. $\partial \hat{K} / \partial s>0$ and $\partial \hat{Y} / \partial s>0$.

2. $\partial \hat{K} / \partial \bar{L}>0$ if $A_{G}>A_{P}(1-s)$, and $\partial \hat{Y} / \bar{L}<0$.

The proposition is easily proved by taking derivatives of the corresponding expressions in (27) and (28). Details can be found in the appendix.

The intuition behind proposition 2 is straightforward and is derived from the combination of the factor reallocation effect and the capital accumulation effect. Assume first that the capital subsidy rate $s$ decreases. Capital becomes a relatively expensive factor of production for the SOE sector, reducing the demand for capital by SOEs. Keeping the period capital stock fixed, capital flows (reallocates) to the private sector, reducing its marginal productivity in that sector. A lower return to capital reduces the consumers' incentives to invest. Thus, capital accumulates at a slower rate and the steady state level of capital decreases. The effect of a decrease in $s$ on output is slightly more complicated. On one hand, for a given TFP level, lower steady state capital implies lower output. On the other hand, capital reallocates to the more productive private sector, increasing overall productivity and, thus, output. Given the assumptions of this model, the former effect is stronger, and a decrease in the capital subsidy rate decreases output. 
Changes in labor requirements have a less straightforward long run effect. In particular, the factor reallocation effect involves the reallocation of both capital and labor across sectors. Assume that the labor requirement $\bar{L}$ is reduced. Capital and labor reallocate to the private sector. Since the private sector uses less capital per worker, the factor reallocation effect reduces the demand for capital. Whether the steady state capital stock increases or decreases depends on the effect of this reallocation on the return to capital (the capital accumulation effect). If capital is more productive relative to labor in the private sector than in the SOE sector, the return to capital increases and consumers have an incentive to accumulate capital at a higher rate, increasing the supply of capital. The condition given in the proposition ensures that the factor reallocation effect is negative and stronger than the capital accumulation effect. Furthermore, a reduction in the labor requirement increases aggregate productivity. This effect is stronger than the factor reallocation effect, and steady state output increases. Notice that if the condition in the proposition is not satisfied, steady state output still increases (as both the capital stock and productivity increase).

\section{Calibration}

Most of the data used in the calibration of the model are taken from the China Statistical Yearbook, issued by the Chinese government. As with any empirical study, the accuracy of the results depends on the accuracy of the reported data. The quality of the Chinese data is questionable, especially for data on output and employment (see Young 2004). For example, SOEs may have people on their payrolls who are not used in production (but have not been laid off either); SOEs' employees may receive other benefits besides their wages, like housing and school benefits, that are paid by the SOEs. Regarding data on the nature of ownership, government officials may have their own private firms that obtain the same privileges as the SOEs (thanks to their connections), or there may be some SOEs that effectively work as private enterprises. There is not much that can be done regarding data on employment and output and, therefore, this paper suffers from the same problems as all papers using Chinese data. Regarding data on ownership, we take a conservative position and define SOEs as narrowly as possible. In particular, we classify "collective" enterprises as private, even though some of them receive benefits from state or local governments.

We follow Young (2004) and drop the agricultural sector from the model. The main reason for doing this is that data on agricultural output only reflect production that is sold in the marketplace, and they are very distorted. We calibrate the parameters of the model in order to match data on the Chinese National Income and Product Accounts, the Chinese 
input-output matrix, and the Chinese participation of SOEs in industry for 1997. Ideally, we would like to calibrate the model to 1978, when China started its economic reforms. Unfortunately, input-output matrices are not available for that year. Furthermore, China did not adopt standard accounting methodology until the 1990s. We chose to calibrate the model to 1997 data since 1997 is the first year for which a complete, meaningful input-output matrix for the Chinese economy exists.

We adjust NIPA and input-output data to the characteristics of the model. We remove the agricultural sector from both sets of data, and we adjust the input-output matrix to balanced trade in order to be consistent with a closed economy model. We normalize GDP in 1997 to be 100, and we measure all variables as a percentage of GDP. Furthermore, we pick labor units so that one unit of labor corresponds to one yuan worth of labor income in 1997. From the 1997 input-output matrix we obtain a capital income of 38.8 and a labor income of 45.5 .

The input-output matrix does not distinguish between private and state-owned enterprises. Therefore, we construct the SOE shares of output and inputs from other tables in the China Statistical Yearbook. The SOE share of capital is constructed from investment data using a Harberger-type perpetual inventory method. We obtain $\theta_{K}=.6$. The SOE share of value added is computed to be $\theta_{Y}=.4$. The SOE labor share is determined endogenously, and it is set up to match a value of SOEs' losses as a percentage of non-agricultural GDP of .6 percent (the 1997 value). Given the problems with employment data mentioned above and the fact that China changed the way employment was measured in 1998, we believe this is a sensible approach.

Production and policy parameters. We jointly calibrate the capital share of income $\alpha$, the tax rate $\tau$, the SOE share of employment $\theta_{L}$, and the interest subsidy rate $s$ from the first order conditions from the producers' problems (2)-(5), the zero profit condition for the private firms, and the SOE profits' condition (7). The technology parameters are then derived directly from the production functions. The corresponding values for these calibrated parameters are:

\begin{tabular}{|r|r|r|r|r|r|}
\hline$\tau$ & $s$ & $\theta_{L}$ & $\alpha$ & $A_{P}$ & $A_{G}$ \\
\hline .29 & .57 & .40 & .36 & 1.45 & 1.05 \\
\hline
\end{tabular}

Notice that in the calibrated economy private firms are 40 percent more productive than SOEs. The parameter $A_{P} / A_{G}$ is crucial for the quantitative results of the paper. We check the robustness of the results relative to this parameter in the sensitivity analysis section. 
Finally, we set the minimum labor requirement $\bar{L}$ to be equal to the SOE share of labor income in 1997.

Preference parameters. We take the time period to be one year, so we set the discount factor $\beta$ to .96. We pick $\rho$ equal to 0 , which implies an intertemporal elasticity of substitution of 1 , within the range considered by the real business cycle theory. First order conditions and consumption data from the input-output matrix determine the rest of the parameters. Government consumption is 13.9 percent of GDP, from the 1997 input-output tables.

Since we are not calibrating to the balanced growth path, we need a rental rate of capital for 1997. We obtain this initial rental rate by dividing the capital income from the inputoutput matrix by an estimate of the capital stock in 1997, obtained using the Harberger-type perpetual inventory method. Technology levels for the SOEs and the private firms can then be inferred from the corresponding production functions.

Adjustment costs of capital. We take the depreciation rate $\delta$ to be 8 percent (the average depreciation rate for the period 1987-1997). In order to infer the parameter $\eta$ notice that, given our choice of adjustment cost function, $1 /(1-\eta)$ is the elasticity of the investmentcapital ratio with respect to the Tobin's q. Since it is difficult to construct meaningful prices for capital in China, we choose to calibrate the parameter to U.S. data and to perform sensitivity analysis for a wide range of parameter values in the sensitivity analysis section. In the tradition of the international real business cycles literature, as reported by Kouparitsas (1998), we set this elasticity to 10, which makes it consistent with aggregate volatility levels of the U.S. investment-capital ratio. This implies a value of $\eta$ of .9 .

Finally, following Kehoe and Prescott (2002) we consider a long run output growth of 2 percent, equal to the secular growth rate of the US economy in the 20th century. This determines a value of $\gamma$ equal to 1.02. We take the population growth parameter $n$ to be equal to 1.01, which roughly equals the average growth rate of employment for the period 1990-1997. Table 1 contains a summary of the calibrated parameters and their sources.

\section{Simulation Results}

In this section we simulate the calibrated model in order to assess the economic effects of reforms in China's SOE sector induced by China's WTO agreement. We take 1997 as the initial period and 2001-2005 as reform period, where policy changes are implemented. We choose this reform period for two reasons. First, even though China's accession to WTO was in December 2001, bilateral negotiations with the bigger member countries had been going on for a while. Second, WTO allows most reforms to be implemented gradually. In particular, 
the required reform in direct subsidies that is the focus of this paper has an implementation period of five years. After the reform period is over, minimum labor requirements and capital subsidy rates stay constant at their 2005 level.

It is important to notice that we have calibrated the economy to capital and investment numbers for 1997 without requiring these numbers to be consistent with the economy being in a balanced growth path in that year. Taking the capital value for 1997 as an initial condition and given the policy parameters for 1997, the economy will evolve to a particular balanced growth path through a transition path. Changing the policy arrangements causes the economy to evolve to a different balanced growth path, through a different transition path.

In 1997, our initial period, China was already in a process of economic reform. In particular, subsidies to SOEs had been declining at steady rates due to the implementation of policies like privatization, sell outs, and closures. In the period 1997-2000, SOE losses as percentage of GDP, our measure of direct subsidies, declined by 44 percent. We match this fact in the model with an annual 2 percent reduction of the minimum labor requirement in the pre-reform period, $1997-2000 .^{10}$

We compare the reformed economy to a benchmark economy in which WTO reforms are not implemented. In the benchmark economy, SOE policies in the reform period behave in the same way as in the pre-reform period: the capital subsidy rate stays constant at the calibrated value for 1997 and the minimum labor requirement continues to decrease at the same rate as in the pre-reform period stabilizing afterwards at its corresponding 2005 level. ${ }^{11}$

The reformed economy, labeled the direct subsidies economy, implements an additional 26 percent reduction in direct subsidies during the reform period, as required by China's WTO accession documents. ${ }^{12}$ This reduction in direct subsidies is obtained through a 6.35 percent decrease in the minimum labor requirement $\bar{L}$ over the reform period. As in the benchmark economy, we assume that $\bar{L}$ stabilizes after the reform period at its 2005 level. In both economies the starting period and the phase out periods of the reforms are known by all economic agents. Notice that by waiting four periods before the reforms start, we are not taking into account any reforms implemented between 1997 and 2001 that were required

\footnotetext{
${ }^{10}$ In this model, there is a one to one relationship between direct subsidies and the minimum labor requirement, $\bar{L}$, since SOE losses are derived from the SOEs' hiring more labor than it is efficient.

${ }^{11}$ This assumption is conservative, since literature on Chinese SOE reform (e.g. Lin, Cai, and Li, 1998) reports that by the late 1990s SOE reforms had slowed down considerably.

${ }^{12}$ According to Annex 5B of the agreement, "Subsidies to be phased out", the subsidies to be phased out during the reform period represent 26 percent of total SOE losses in 1997 . We assume that the targeted subsidies are subsidies that would not have been eliminated otherwise.
} 
during the negotiation period and which are also linked to the WTO agreement. Abstracting out from these reforms makes our estimates conservative.

In our simulations we solve for the equilibrium of the stationary economy. Given a set of policies, in steady state our environment is equivalent to a two-sector closed economy growth model and the steady state can be computed analytically as in section $4.2 .{ }^{13}$ In all simulations, we assume that the changes in policy occur only during the reform period (2001-2005). After the reform period policies stay fixed at their values in 2005. Therefore, the steady state policies depend on the reforms implemented during the reform period and, thus, under each scenario the stationary economy converges to a different steady state. In order to compute the transition path, we assume that the economy reaches its steady state in $T=50$ periods. In all our simulations, the economy is practically at its steady state after 35 periods. Increasing the value of $T$ does not change our results.

In what follows, we first derive intuition on how the model works by plotting the transitional paths of the main economic variables for the period 1997-2005 and comparing them to the actual data for the Chinese economy in that period. In the second subsection we assess the effects of reducing direct subsidies by comparing the transitional dynamics of the direct subsidies economy with those of the benchmark economy. The advantage of this methodology is that it isolates the effects of the SOE reforms from other changes occurring in the economy. In particular, any aspects of the economy that are not affected by the given change in SOE policy are washed out in our comparison and, thus, we can abstract from them in the model. The variables that we report are all in per-capita terms, with the level variables detrended.

\subsection{Model and Data}

In this section we show the evolution of the main economic variables in the direct subsidies economy for the period 1997-2005 and we compare it to actual Chinese data. We would like to emphasize that the model developed in this paper is quite simple and does not have some relevant features of the Chinese economy that have most surely contributed to China's economic performance during the period of study (e.g. international trade, foreign investment.) Given the focus of our paper, abstracting out from these features is not restrictive as long as they have similar effects in the benchmark and the reformed economy. ${ }^{14}$ Differ-

\footnotetext{
${ }^{13}$ Notice that given our assumptions on the adjustment costs of capital, in steady state these adjustment costs are absent and capital depreciates at a constant rate $\delta$.

${ }^{14}$ We have run the experiments for a more complicated version of the model with international trade and open capital markets, and we find that welfare gains of reducing direct subsidies are similar to the ones
} 
ences in the evolution of the relevant economic variables may be very substantial, though, when considering the reformed economy in isolation. Therefore, inaccuracy in matching the actual transitional dynamics for the Chinese economy does not necessarily imply that the predictions of the model economy are poor. As long as the inaccuracies are similar in both the benchmark economy and the direct subsidies economy, they will be washed out in our comparisons and they will not affect the results of the exercises performed in this paper. In all figures presented below, we detrend both the data from the model and the actual data by the calibrated trend, which assumes a 2 percent annual output growth. Notice that since the model abstracts out from the primary sector, all variables are computed for the secondary and tertiary sector only.

Figures 1 compares real GDP indices from the model and the actual data. The model roughly matches the trend but it misses the growth rate: real GDP grows much faster in the data than in the model. This suggests that there is some important factor that contributes to the high growth rates in China that is not accounted for by the model. The figure also presents data on the Chinese real GDP level detrended at a 7.5 percent growth rate, chosen to roughly match TFP growth in the data for the period 1997-2005. We observe that even when the data is detrended at the higher rate, output strill grows faster in the data than in the model. Notice, again, that as long as this factor does not change substantially when SOE subsidies are reduced, our strategy of comparing the reformed economy to a benchmark washes it out.

Figures $2 \mathrm{~A}$ and $2 \mathrm{~B}$ present a detailed analysis of the evolution of TFP for the model and the data, respectively. Following Kehoe and Prescott (2002) we perform a growth accounting exercise to separate the effects of technological improvements in TFP (the factor reallocation effect) from those of capital accumulation (the capital accumulation effect). In particular, we decompose the logged GDP per worker as:

$$
\log Y_{t}=\gamma t+\frac{1}{1-\alpha} \log A_{t}+\frac{\alpha}{1-\alpha} \log \frac{K_{t}}{Y_{t}}
$$

where $Y_{t}$ is real GDP per worker, $K_{t} / Y_{t}$ is the capital-output ratio, $\alpha$ is the capital share of income (which has a calibrated value of .36), and $\gamma$ is the long run growth rate. The first two terms on the right hand side of the equation are the TFP related terms and are calculated as a residual. In this environment, the capital accumulation effect is captured by the contribution of the capital-output ratio to growth, whereas the factor reallocation effect is captured by the contribution of the TFP terms. In the model the factor reallocation effect after liberalization is clearly observed in figure 2A. After 2001, the TFP term accounts for a higher proportion of presented in the paper. 
GDP growth than it did in the pre-reform period. Figure 2B shows the same decomposition for the actual data. We do not observe the increase in the factor redistribution effect in the data after 2001. There are two main reasons why this may be the case, both of them not directly related to SOE policy: (i) an abrupt increase in employment in the secondary sector after 2003, matched with a similar reduction in agricultural employment and, more importantly, (ii) a sharp increase in investment since 2003, which cannot be accounted by the model. This high increase in investment is primarily due to an increase in private investment ("self-raising funds" which doubles its growth rate after 2003, and "foreign direct investment", which also experiences a sharp increase after 2002.) This increase in private investment coincides with the announcement by the government in 2002 that it would allow private investment in formerly restricted sectors.

Data on investment-to-output ratios and consumption-to-output ratios are plotted in figures 3 and 4 . In the data, the investment-to-output ratio is almost constant in the prereform period, and it increases after 2001 at an average annual rate of 6.8 percent. The consumption-to-output ratio does not vary much from 1997-2000 and decreases at a sharp rate after 2001. The model is not able to match these facts: investment-to-output is almost constant after 1998, and consumption-to-output slightly increases over the whole period of study. Therefore, the data suggest a sharp increase in investment after WTO accession, matched with a smaller decrease in the consumption-to-output ratio, which is not present in the model. The reduction in the consumption-to-output ratio reflects also an increase in domestic investment.

Figure 5 plots the direct subsidies-to-GDP ratio for the actual data and the model economy. Recall that direct subsidies are equivalent in this paper to SOE losses. We observe that the graphs for the model and the actual data are pretty close to each other. Since we calibrate the model to match the decrease in direct subsidies during the pre-reform period, it is no surprise that the graphs are close in this period. More surprising is the match in the reform period, 2001-2005, where direct subsidies-to GDP decreased from .3 percent in 2001 to .1 percent in 2005. We interpret this as China actually implementing the WTO requirements, and reducing subsidies in the amount requested. The fact that the SOE subsidy ratio does not decrease further in the data can be taken as anecdotal evidence that the SOE reforms implemented prior to WTO accession were almost completed, and that China needed a further push, like WTO requirements, to be able to implement further reforms. The flatter curve in the period 1999-2001 is also consistent with this argument.

The evolution of the SOE shares of output, employment, and investment is plotted in figures 6-8. The SOE shares of output and employment decrease both in the model and in 
the actual data (figure 6). Both graphs show a slow down in the rate of decrease of these SOE shares during the pre-reform period, and an acceleration in the reform period, especially for the level of output. The graphs also show similar rates of decrease of the output and labor shares for the model and the actual data during the reform period. China changed the way it measured employment and wage indicators in $1998 .{ }^{15}$ The change affected mainly SOE indicators. We have adjusted 1997 SOE employment to make it compatible. Since no official adjustment has been provided by the government, we suggest to take the first two points in figure 7 with caution. The behavior of the SOE share of investment differs in the model and the data, especially during the pre-reform period (figure 8). Whereas in the model the investment share decreases over the whole period, in the data it increases from 1997 to 1999 and it decreases at a much faster rate from 1999 to 2002. The rate of decline seems to be higher after 2002 than in previous years, reflecting perhaps the fact that a large proportion of the new investment made in China after WTO accession was done in the private sector.

Finally, figure 9 shows the growth rate of labor earnings relative to GDP. Labor earnings grew much faster than GDP in the data (between 2 and 2.5 times faster), while in the model they grew much slower (about half the GDP growth rate.) The relative growth rate in the data does not present different patterns for the pre- and post-WTO periods, whereas in the model labor earnings grow slightly slower than GDP after WTO accession. This result is probably related to the different patterns of investment in the model and the data (figure 3): after WTO accession, investment slows down in the model, slowing down the growth rate of capital accumulation and thus the growth rate of the marginal productivity of labor. In the data, investment increases much faster and so does the marginal productivity of labor.

Summarizing, the model is able to match the trends of most of the variables analyzed, but it misses the growth rates of some of them. In particular, the model matches surprisingly well the decrease in the direct subsidy to GDP ratio during the reform period and the decrease in the SOEs shares of output and employment. These results suggest that the modeling assumptions regarding the relationship between direct subsidies and employment in SOEs are sensible. The model is less successful at predicting variables related to investment. It predicts a much lower investment-to-output ratio than what we see in the data, it under-predicts the growth rate of labor earnings, and it does not match well the SOE share of investment. This suggests that any model aimed at explaining the high growth rates experienced by the Chinese economy has to be able to account for China's high investment-to-output ratios.

\footnotetext{
${ }^{15}$ In particular, according to the China Statistics Yearbook (2006), data on employment and wages in urban areas do not include, after 1998, people "who have left their working units with their working records and allowances kept in their working units".
} 


\subsection{Comparisons with the benchmark}

Figures 10-18 present the detrended transitional dynamics for all the policy scenarios that we consider in the paper. In all figures the data are expressed as deviations from the benchmark economy. Figures 10 and 11 present deviations from benchmark of real GDP per capita and GDP growth rates, respectively. Notice that, in the initial periods, before reforms are implemented, the GDP level and the growth rate are higher in the benchmark economy than in the direct subsidies economy. In particular, pre-reform growth rates are 2 percent below benchmark. Once the reforms start, though, the growth rate is higher in the reforming economy. The intuition for this result is the following: knowledge of future reforms in the SOE sector together with the adjustment costs of capital imply lower initial investment in the SOE sector for the direct subsidies economy. This lower investment is not totally compensated by higher investment in the private sector (see figure 12). ${ }^{16}$ The result is lower initial investment, lower GDP levels, and lower growth. In the reform period, higher growth rates are achieved through reallocation of resources to the more efficient private sector. As labor is freed from the SOEs, both capital and labor move to the private sector (the factor reallocation effect). The SOE's share of production decreases (figure 13) and overall productivity increases (figure 14). The lower investment rates imply a lower capital stock in the reformed economy (figure 15). The increase in TFP more than compensates for the decrease in investment, leading to a long run GDP level in the detrended economy that is slightly above benchmark.

Figures 16 and 17 plot the evolution of wages and interest rates relative to the benchmark. In the pre-reform period, both wages and interest rates are higher than benchmark, reflecting the expectations of higher overall productivity in the future. Once productivity gains have been materialized, the SOE's share of output is smaller than in the benchmark economy, and low interest rates reflect the lesser need for capital in the reformed economy. Notice that wage rates become smaller than in the benchmark at the beginning of the reform period, indicating that as capital becomes relatively cheap, both types of firms increase the capital intensity in their production.

Finally, we find that lifetime welfare, in terms of equivalent variation, is 1.5 percent higher in the direct subsidies economy. ${ }^{17}$ This higher welfare is driven by both the factor

\footnotetext{
${ }^{16}$ Since capital is not subsidized in the private sector, it is relatively more expensive compared to labor than for the SOE sector. The private sector, thus, uses less capital per worker than the SOE sector.

${ }^{17}$ That is, we solve for the value of $\mu$ such that $U\left((1+\mu) c_{b}\right)=U(c)$, where $U$ is lifetime welfare, $c_{b}$ is the series of equilibrium consumptions in the benchmark period, and $c$ is the series of equilibrium consumptions in the direct subsidies' economy. Given the utility function listed in $(8), \mu=\exp (1-\beta n)\left(U(c)-U\left(c_{b}\right)\right)-1$.
} 
reallocation effect and the capital accumulation effect. As resources reallocate from the (less productive) SOE sector to the (more productive) private sector, the economy becomes more efficient. Productivity increases, increasing welfare. The capital accumulation effect has two offsetting effects on welfare. First, as the share of output produced by private firms increases, there is a lesser need to invest in capital so a bigger share of output is now devoted to consumption. This reinforces the increase in welfare. On the other hand, as less capital is accumulated, there is less output produced, which tends to reduce welfare. In this experiment, the first effect dominates. Figure 18 plots consumption levels relative to benchmark. Consumption is consistently 1 percent above benchmark, even though the output level is below benchmark for most of the pre-reform and reform periods.

\section{Sensitivity analysis}

We perform sensitivity analysis on three parameters: the capital adjustment costs parameter, the minimum labor requirement parameter, and the SOEs' relative TFP level. The latter is very important, since it determines the relative inefficiency of the SOEs, which in turn is key in determining the magnitude of the welfare gains from shrinking the SOE sector.

Given the nature of the numerical experiments in this paper, performing sensitivity analysis involves solving for the benchmark economy and the direct subsidies economy under the new parameter values and comparing their transitions paths and welfare levels.

Capital adjustment costs parameter. The capital adjustment cost parameter is relevant in determining the length of the transition process. By limiting capital mobility, this parameter slows down the transition to the balanced growth path. It also affects the SOE's investment decisions in the initial periods. High adjustment costs make reallocating capital more difficult and, therefore, increase the costs of committing capital to a specific industry or sector. In order to understand the effects that the adjustment costs have in our results, we reproduce the first numerical experiment (comparing the direct subsidies economy to the benchmark economy) for a wide range of values of the parameter $\eta$. We find that the welfare gains of liberalization are pretty stable with respect to the value of the parameter. Increasing the adjustment costs so that $\eta=.5$, which implies an elasticity of the investment-capital ratio with respect to the Tobin's q of 2 , would decrease the welfare gains of reform by .13 percentage points. Eliminating the adjustment costs of capital would increase welfare gains from reducing direct subsidies by .04 percentage points. By assuming adjustment costs of capital, the model has a slower transition and delivers slightly more conservative estimates of the gains from reform than we would obtain if we ignored such costs. Table 2 presents 
the welfare gains of liberalization for a wide range of values for the parameter $\eta$.

Minimum labor requirement parameter. Given that in this model direct subsidies to SOE are equivalent to employment subsidies, we consider the effects of changing the SOEs' employment parameter. In particular, we consider the welfare effects of additional reductions in the labor constraint (relative to benchmark) over the reform period, first by 1 percent and then by 13 percent, instead of the calibrated value of 6.3 percent. Reducing the labor constraint by 1 percent over the reform period produces welfare gains of direct subsidy reform of the order of .2 percent (compared to welfare gains of 1.5 percent obtained in our calibrated economy). Reducing the labor constraint by an additional 13 percent over the reform period produces welfare gains of 3.2 percent. These results suggest that the extent of the welfare gains derived from SOE reforms induced by WTO is mainly determined by their effects on SOE employment. Figures 19-21 show deviations from benchmark of real GDP growth, SOEs' share of output, and TFP levels, respectively, for each of the different reductions in the minimum labor requirement considered above.

Relative SOE productivity. The last set of parameters on which we do sensitivity analysis are parameters that determine the relative inefficiency of the SOE sector. The relative inefficiency of the state sector is given by the ratio of productivity levels $A_{P} / A_{G}$. We rerun the experiment in section 5.1 under two different situations. First, we modify $A_{G}$ so that the ratio between private and state productivity levels is 2 percent lower than in the calibrated economy. Second, we modify $A_{G}$ so that the ratio between private and state productivity levels is 2 percent higher than in the calibrated economy. We compute the equilibrium of the benchmark economy and the direct subsidies economy under the new set of parameters and compare welfare levels. When increasing the SOEs' efficiency direct subsidy reform produces welfare gains that are .05 percentage points lower than in the original experiment. When the SOEs' efficiency is reduced, the welfare gains of reform are .05 percentage points higher than in the original experiment.

Given the importance of the relative SOE productivity in determining the results in this paper, we perform a third sensitivity check. We recalibrate the model using data for the year 2000, another year for which the Chinese government reports an input-output matrix. The values of the variables needed to calibrate the parameters in table 1 vary relatively little with respect to 1997, with the only exception of the SOE losses to (non-agricultural) GDP ratio, which is halved (the values are .3 percent for 2000 and .6 percent for 1997.) Using data for 2000, we obtain a calibrated value for $A_{P} / A_{G}$ equal to 1.39 , only 1 percent bigger than the 1997 value. Therefore, for the two years for which we have input-output data, the relative productivity of SOEs is practically the same. 


\section{The role of subsidies to capital}

WTO accession may have implicit effects on the SOE sector that are difficult to assess. In particular, it is hard to quantify how much the preferential lending rates from state banks to the SOEs will change with the increase in competition in the financial sector driven by WTO provisions. Nevertheless, we believe that these effects are potentially important and, therefore, that it is worthwhile presenting representative numerical experiments that illustrate the welfare effects of a reduction in the capital subsidy rate alone and in combination with a reduction in direct subsidies. We consider two additional policy scenarios that we compare to the benchmark economy. In the first scenario only capital subsidies are reduced. In the second scenario we reduce both capital and direct subsidies simultaneously.

\subsection{Reduction in subsidies to capital}

This section considers an economy that implements a 2 percent gradual reduction in the capital subsidy rate to SOEs, $s$, during the reform period. Minimum labor requirements are kept at the same levels as in the benchmark economy and, therefore, direct subsidies to SOE are endogenously determined. We label this new scenario the capital subsidies economy. Even though the reduction in the capital subsidy rate that we consider may seem small, the reduction in subsidies to capital is substantial in absolute terms. It amounts to about 3 percent of GDP over the reform period, or to an annual reduction in capital subsidies equivalent to twice the value of total SOE losses for $1997 .^{18}$

The transitional dynamics of the capital subsidies economy are plotted in Figures 1018. The main effect of reducing subsidies to capital is a reduction in the rate of capital accumulation in the economy (capital accumulation effect). As capital becomes relatively more expensive for the SOEs once reforms are enacted, they shift their input mix in favor of labor. Given that capital cannot move freely across industries or sectors, SOEs respond to the future increase in the costs of capital by investing less during the pre-reform periods. The economy accumulates capital at a lower rate and both the real GDP level and the real GDP growth remain below benchmark. Nevertheless, TFP levels are consistently above benchmark (factor reallocation effect). Compared to the direct subsidies economy, the TFP levels increase faster in the pre-reform periods and more slowly afterwards. This result is driven again by the SOEs' expectations of higher costs of capital in the future. SOE shares are slightly below benchmark and welfare is .6 percent higher than in the benchmark

\footnotetext{
${ }^{18}$ This is due to the fact that the calibrated capital subsidy rate is 57 percent, with total capital subsidies amounting to 80 percent of GDP in 1997 for the benchmark economy.
} 
economy. It is important to notice that since the labor restriction has not changed in this experiment, SOEs are making bigger losses in the reformed economy than in the benchmark. In particular, SOEs' direct subsidies as a percentage of GDP increase by 43 percent over the reform period.

This experiment shows that small reductions in capital subsidy rates can produce significant welfare effects. Therefore, quantifying the effect on capital subsidies of the WTOinduced increases in competition in the financial market may be important, and it is a subject for future research.

\subsection{Reduction in both direct subsidies and capital subsidies}

This section considers an economy that jointly implements direct and capital subsidies' reforms. In particular, we consider a policy scenario where direct subsidies are reduced by an additional 26 percent over the reform period compared to the benchmark (as in the direct subsidies economy), at the same time that the capital subsidy rate is lowered by 2 percent (as in the capital subsidies economy). The rationale behind this experiment is that more competition in the financial market may require deeper reforms in the labor market given any targeted reduction in direct subsidies, thus amplifying the welfare effects of the WTO-required reforms. We label this economy the both subsidies economy.

For a given minimum labor requirement, reducing the capital subsidy rate increases the costs of production and SOEs make higher losses. Therefore, a much larger reduction of the minimum labor requirement is needed in order to lower the direct subsidies by the required amount. In particular, with a 2 percent reduction in the subsidies to capital, we need a 20.1 percent reduction in the labor requirement in order achieve an additional reduction of 26 percent in direct subsidies.

Transitional dynamics for the both subsidies economy are also presented in Figures 10-18. In this experiment, the factor reallocation effect and the capital accumulation effect reinforce each other. The joint implementation of the subsidy policies causes a faster reallocation of resources towards the private sector. The SOEs share of output decreases faster in both the pre-reform and the reform period (figure 13), increasing overall productivity levels much faster than in the direct subsidies economy (figure 14). Since the private sector is less capital intensive, there is less need for investment (figure 12), reducing the amount of capital in the economy and the real GDP level (figure 10) much more than in the direct subsidies economy. The highest discrepancy in terms of GDP levels between these two economies occurs in the first year of the reform period. Real GDP growth is smaller during the pre- 
reform period and higher in the reform period than in the direct subsidies economy (figure 11). The lower growth rate of the initial periods emphasizes the fact that the economy reacts to the knowledge of future reduction in subsidies before those are actually adopted. The effect on wages and the interest rate are similar to the direct subsidies' economy, with the discrepancies relative to benchmark also amplified.

Finally, the welfare gains for the both subsidies economy are of 5.4 percent, well above the 1.5 percent obtained in the direct subsidies economy. Most of the welfare gains are driven by the extra reduction in SOE employment that is needed in order to comply with WTO requirements when a reduction in capital subsidies is also implemented.

\section{Conclusion}

By becoming a member of the WTO China accepted regulations that imposed reductions of government subsidies to its state-owned sector. In this paper we quantitatively assess the economic effects of these regulations. We develop a dynamic applied general equilibrium model where the state-owned sector is explicitly modelled. We find that the welfare effects of reducing the ratio of direct-subsidies to GDP by an additional 26 percent during the reform period (which is on the lines of China's WTO accession protocol) are in the order of 1.5 percent. This is a conservative measure, since it does not include effects on the SOE sector from provisions that may reduce the ability of state banks to subsidize SOE's capital. A contemporary reduction in the capital subsidy rate to SOEs by 2 percent increases the welfare gains to 5.4 percent. The welfare benefits from the reduction in SOE subsidies are derived from reallocating factors of production from the SOEs to more efficient private firms, and the changes in investment decisions that this move generates.

This paper has several important implications that extend beyond the case of China. First, it shows that transitional dynamics are important in understanding the full effects of industrial subsidy reform. Reforming economies grow below benchmark in the pre-reform periods and above benchmark after reform has started. Considering only long run implications of the reforms would miss out this non-monotonicity. Second, overall welfare benefits from trade liberalization may be significantly higher than the benefits derived from pure trade policy reform. Trade liberalization may induce a reallocation of resources from less productive, subsidized firms to more efficient private firms, with the subsequent increase in overall productivity and welfare. This is especially the case in developing countries that have large and highly inefficient state sectors. For such countries abstracting from modeling the state sector may lead to a significant underestimation of the benefits of trade liberalization. 
The framework in this paper has some limitations that we expect to address in future research. First, we model the aggregate economy. Further disaggregation would allow us to capture inter-industry effects, which would be useful for countries that have industryspecific subsidies. Second, we do not model unemployment costs. Adding adjustment costs of employment would further smooth the transition process. Finally, we ignore monopoly power and agency issues that are often present in state-owned or subsidized sectors and that may affect SOEs' productivity. 


\section{Appendix}

\subsection{Proof of the Propositions}

\subsubsection{Proof of proposition 1}

1. Replace $\bar{L}$ with the corresponding values for the policies. For the last inequality, notice that $A(0, \bar{L})=(H / N)^{1-\alpha} A_{G}$. The condition follows from the fact that $H>N$ if and only if $\bar{L}<N$.

2. Using expression (22), $\partial A / \partial \bar{L} \leq 0$ if and only if $\partial Y_{G} / \partial \bar{L} \leq \partial Y_{P} / \partial \bar{L}$. Using (20) and (21), and letting $\kappa_{G}=K_{G} / \bar{L}$ and $\kappa_{P}=K_{P} / L_{P}$, where $L_{P}=N-\bar{L}$, we obtain:

$$
\frac{A_{G}}{A_{P}}\left(\frac{\kappa_{G}}{\kappa_{P}}\right)^{\alpha-1} \leq \frac{\alpha \partial K_{G} / \partial \bar{L}+(1-\alpha) \kappa_{P}}{\alpha \partial K_{G} / \partial \bar{L}+(1-\alpha) \kappa_{G}}
$$

From (2) and (4) we obtain that:

$$
\frac{\kappa_{G}}{\kappa_{P}}=\left(\frac{A_{G}}{A_{P}(1-s)}\right)^{1 /(1-\alpha)} .
$$

Therefore, the expression above holds if and only if:

$$
-s \alpha \partial K_{G} / \partial \bar{L}+(1-\alpha) \kappa_{G}(1-s-B) \leq 0 .
$$

Given that

$$
\partial K_{G} / \partial \bar{L}=K(H+\bar{L}(B-1)) / H^{2}>0
$$

a sufficient condition for this expression to hold is $A_{G} \leq A_{P}(1-s)^{\alpha}$, which is condition (6). Notice that the expression above is equal to zero only if both $s=0$ and $A_{P}=A_{G}$.

3. To prove this, we use the fact that $\partial B / \partial s=-B /[(1-\alpha)(1-s)]$ and $\partial H / \partial s=$ $(N-\bar{L})(\partial B / \partial s)$. Taking the derivative of $A(s, \bar{L})$ with respect to $s$ and simplifying, using these expressions, we obtain:

$$
\operatorname{sign}\left(\frac{\partial A}{\partial s}\right)=\operatorname{sign}\left(\frac{-s \bar{L}(N-\bar{L})}{1-s}\right) .
$$

The expression on the right hand side is always non-positive, and it is equal to zero only when $s=0$ or $\bar{L}=0$ or $\bar{L}=N$. 


\subsubsection{Proof of proposition 2}

1. Rewrite $\hat{K}$ as:

$$
\hat{K}=\left(\frac{\alpha(1-\tau) A_{G}}{\hat{r}(1-s)}\right)^{1 /(1-\alpha)}(\bar{L}+B(N-\bar{L})) .
$$

Then, taking derivatives:

$$
\frac{\partial \hat{K}}{\partial s}=\left(\frac{(1-\tau) A_{G} \alpha}{\hat{r}(1-s)}\right)^{1 /(1-\alpha)} \frac{\bar{L}}{(1-\alpha)(1-s)}
$$

The expression above is non-negative, and it is strictly positive for $\bar{L}>0$.

Rewriting $\hat{Y}$ as:

$$
\hat{Y}=\hat{Y}_{P}+\hat{Y}_{G}=\left(\frac{(1-\tau) A_{G} \alpha}{\hat{r}(1-s)}\right)^{1 /(1-\alpha)}\left(A_{G} \bar{L}+A_{P} B^{\alpha}(N-\bar{L})\right)
$$

we obtain:

$$
\frac{\partial \hat{Y}}{\partial s}=\left(A_{G} \frac{(1-\tau) \alpha}{\hat{r}}\right)^{\alpha /(1-\alpha)} \frac{\bar{L} A_{G}}{(1-\alpha)(1-s)} .
$$

This expression is non-negative, and it is strictly positive for $\bar{L}>0$.

2. Taking the derivative of $\hat{K}$ with respect to $\bar{L}$, we obtain:

$$
\frac{\partial \hat{K}}{\partial \bar{L}}=\left(\frac{\alpha(1-\tau) A_{G}}{\hat{r}(1-s)}\right)^{1 /(1-\alpha)}(1-B)
$$

which is strictly negative if $A_{G}>A_{P}(1-s)$.

Taking the derivative of $\hat{Y}$ with respect to $\bar{L}$ in expression (28) we obtain:

$$
\frac{\partial \hat{Y}}{\partial \bar{L}}=\left(\frac{\alpha(1-\tau) A_{G}}{\hat{r}(1-s)}\right)^{\alpha /(1-\alpha)}\left(-A_{P} B^{\alpha}+A_{G}\right)
$$

Notice that the second term is negative if condition (6) is satisfied. 


\section{References}

[1] Brandt, L., C. Hsieh, and X. Zhu, 2007. "Growth and Structural Transformation in China," in Brandt L. and T. Rawski, eds. China's Great Economic Transformation, Cambridge University Press: New York.

[2] Branstetter, L. and R. Feenstra, 2002. "Trade and Foreign Direct Investment in China: a Political Economy Approach." Journal of International Economics 58, 335-58.

[3] Brooks, R., 2004. "Labor Market Preformance and Prospects," in Prasad, et al., eds. China's Growth and Integration into the World Economy: Prospects and Challenges. International Monetary Fund.

[4] Chen, Y. and I. Diwan, 2000. "When the Bureaucrats Move out of Business: A CostBenefit Assessment of Labor Retrenchment in China." World Bank Working Papers 2354.

[5] Claro, S., 2001. "Tariff and FDI Liberalization: What to Expect from China's Entry into the WTO?" Manuscript.

[6] Fernández de Córdoba, G. and T. Kehoe, 1999. "Capital Flows and Real Exchange Rate Fluctuations Following Spain's Entry into the European Community." Journal of International Economics 51, 49-78.

[7] Fan, M. and Y. Zheng, 2001. "China's Tariff Reductions and WTO Accession: A Comparative General Equilibrium Analysis," in Lloyd, P. and X. Zhang eds. Models of the Chinese Economy. Elgar. Northampton: Massachusets, 221-35.

[8] Frazier, M., 1999. "Coming to Terms with the 'WTO Effect' on US China Trade and China's Economic Growth." NBR Briefing. The National Bureau of Asian Research.

[9] Ghosh, M. and J. Walley, 2000. "State-Owned Enterprises, Shirking, and Trade Liberalization." NBER Working Paper 7696.

[10] Hay D., D. Morris, G. Liu, and S. Yao, 1994. Economic Reform and State-Owned Enterprises in China, 1979-198\%. Oxford University Press. New York.

[11] Hsieh, C. and P. Klenow, 2007. "Misallocation and Manufacturing TFP in China and India." NBER Working Paper 13290.

[12] Huang Y. and R. Duncan, 1997. "Which Chinese State-Owned Enterprises Make Losses?" Asian Pacific Journal of Economics and Business 1, 41-52.

[13] Ianchovichina, E. and W. Martin, 2001. "Trade Liberalization in China's Accession to the World Trade Organization." Journal of Economic Integration 16, 421-45. 
[14] Ianchovichina, E. and W. Martin, 2004. "Economic Impacts of China's Accession to the WTO," in Bhattasali D., L. Shantong, and W. Martin, eds. China and the WTO: Accession, Policy Reform, and Poverty Reduction Strategies. World Bank.

[15] Kehoe, P. and T. Kehoe, 1994. "Capturing NAFTA's Impact with Applied General Equilibrium Models." Federal Reserve Bank of Minneapolis Quarterly Review 18, 17-34.

[16] Kehoe, T. and E. Prescott, 2002. "Great Depressions of the Twentieth Century." Review of Economic Dynamics 5, 1-18.

[17] Kouparitsas, M., 1998. "Dynamic Trade Liberalization Analysis: Steady State, Transitional and Inter-industry Effects." Federal Reserve Bank of Chicago Working Papers WP-98-15.

[18] Lardy, N., 2002. Integrating China into the Global Economy. Brookings Institution Press. Washington.

[19] Li W., 1997. "The Impact of Economic Reform on the Performance of Chinese State Enterprises, 1980-1989." Journal of Political Economy 105, 1080-1106.

[20] Lin J., F. Cai, Z. Li, 1998. "Competition, Policy Burdens, and State-Owned Enterprise Reform." American Economic Review 88, 422-427.

[21] Lucas, R. and E. Prescott, 1971. "Investment under Uncertainty." Econometrica 39, 659-81.

[22] McKibbin, W. and K. Tang, 2000. "Trade and Financial Reform in China: Impacts on the World Economy." World Economy 23, 979-1003.

[23] Papageorgiu D., A. Choksi, and M. Michaely, 1990. Liberalizing Foreign Trade in Developing Countries. The Lessons from Experience. The World Bank. Washington D.C.

[24] Perkins, D., 1994. "Completing China's Move to the Market." Journal of Economic Perspectives 8, 23-46.

[25] Restuccia, D. and R. Rogerson, 2007. "Policy Distortions and Aggregate Productivity with Heterogeneous Plants." NBER Working Paper 13018.

[26] Rumbaugh, T. and N. Blancher, 2004. "International Trade and Challenges of WTO Accession," in Prasad, et al. China's Growth and Integration into the World Economy: Prospects and Challenges. International Monetary Fund. Washington D.C.

[27] Schmitz, J., 2001. "Government Production of Investment Goods and Aggregate Labor Productivity." Journal of Monetary Economics, 47, 163-87. 
[28] Sicular, T., 1995. "Going on the Dole: Why China's State Enterprises Choose to Lose." Manuscript.

[29] Tiwari, P., 2002. "Dual Labor Markets and Trade Reform in China." Journal of Policy Reform 5, 101-114.

[30] Walmsley, T. and T. Hertel, 2001. "China's Accession to the WTO: Timing is Everything." World Economy 24, 1019-49.

[31] Wang, Z., 1999. "The Impact of China's WTO Entry on the World Labour-Intensive Export Market: A Recursive Dynamic CGE Analysis." World Economy 22, 379-405.

[32] Wei Z., O. Varela, and K. Hassan, 2002. "Ownership and Performance in Chinese Manufacturing Industry." Journal of Multinational Financial Management 12, 61-78.

[33] World Bank, 2004. China and the WTO: Accession, Policy Reform, and Poverty Reduction Strategies. World Bank. Washington D.C.

[34] Yin X., 1998. "The Macroeconomic Effects of Waiting Workers in the Chinese Economy." Journal of Comparative Economics 26, 150-164.

[35] Yin X., 2001. "A Dynamic Analysis of Overstaff in China's State-Owned Enterprises." Journal of Development Economics 66, 87-99.

[36] Young A., 2003. "Gold in Base Metals: Productivity Growth in the People's Republic of China during the Reform Period." Journal of Political Economy 6, 1220-1261. 


\begin{tabular}{|c|c|c|c|}
\hline Parameter & Symbol & Value & Source \\
\hline \multicolumn{4}{|c|}{ Production Parameters } \\
\hline Capital Share & $\alpha$ & 0.36 & (a) \\
\hline Productivity, Private Sector & $A_{P}$ & 1.45 & (a) \\
\hline Productivity, SOEs & $A_{G}$ & 1.05 & (a) \\
\hline Growth rate, productivity & $\gamma$ & 1.02 & US trend \\
\hline \multicolumn{4}{|c|}{ Investment Parameters } \\
\hline Adjustment Costs Parameter & $\eta$ & 0.90 & US I/K volatility \\
\hline \multicolumn{4}{|c|}{ Preference Parameters } \\
\hline Discount Rate & $\beta$ & 0.96 & one-year period \\
\hline Elasticity Parameter & $\rho$ & 0.00 & within $\mathrm{RBC}$ range \\
\hline \multicolumn{4}{|c|}{ Policy Parameters } \\
\hline Production Tax & $\tau$ & 0.29 & (a) \\
\hline Government Consumption & $G$ & 0.14 & $\mathrm{I} / \mathrm{O}$ \\
\hline Capital subsidy rate & $s$ & 0.57 & (a) \\
\hline Initial SOE labor share & $L_{G} / N$ & 0.40 & (a) \\
\hline \multicolumn{4}{|c|}{ Initial Values } \\
\hline Initial Capital/GDP & $K_{0}$ & 2.23 & K series \\
\hline Initial Interest Rate & $r_{0}$ & 0.17 & $\mathrm{I} / \mathrm{O}$ and $\mathrm{K}$ series \\
\hline Initial GDP & $Y$ & 1.00 & I/O (normalized) \\
\hline
\end{tabular}

Table 1: Economic parameter values. (a) Jointly calibrated (see text).

\begin{tabular}{|l|r|r|r|r|}
\hline$\eta$ & .5 & .7 & .9 & .99999 \\
\hline welfare gains & 1.43 & 1.50 & 1.56 & 1.60 \\
\hline
\end{tabular}

Table 2: Welfare gains for different adjustment costs. No adjustment costs corresponds to the situation $\eta=1$. 